\title{
An Analysis of the Factors Deterring the Students from Participating in Exchange Programs at Tishk International University.
}

\author{
Aws Y. Abed ${ }^{1} \&$ Zainab A. Alani ${ }^{2}$ \\ ${ }^{1}$ Department of Business Management, Faculty of Administrative Sciences, Tishk International University, Erbil, Iraq \\ Correspondence: Aws Y. Abed, TIU, Department of Business and Management, Erbil, Iraq. \\ Email: aws.yhya@tiu.edu.iq \\ ${ }^{2}$ Department Law, Faculty of Law, Tishk International University, Erbil, Iraq
}

Doi: 10.23918/ejmss. v1i3p34

\begin{abstract}
This study aims to check the attitudes of Tishk International University (TIU) students towards student exchange programs in terms of awareness, tendency, and challenges related to it. The study used an online questionnaire survey and the sample consisted of 150 students of Business faculty but only 100 valid responses were collected. The main findings of this study indicate an awareness and interest in student exchange programs, but the students are not seriously considering participating in such programs. The main channel for their information is word of mouth and the university employees. The study also found that the main factors limiting student participation were the language and that they prefer to do a full degree abroad after finishing their study and not the one-semester study that TIU provides. Oddly, the visa was not reported as an issue. Furthermore, the results were discussed and translated into recommendations for the university and paved the way for future studies on this topic.
\end{abstract}

Keywords: student exchange programs, student mobility, study abroad, challenges, internationalization.

\section{Introduction:}

Sending students to study abroad is one of the goals of higher education in which can help students to be exposed to other cultures and education systems and more importantly, getting proper training (brain train). Universities as an entity that follows higher education instructions and in competition with each other are continuously pursuing to provide studying abroad opportunities and promoting student exchange programs to achieve their goals.

Tishk International University in KRG (Kurdistan Region of Iraq)/Iraq is one of the top private universities in KRG which follows the European system (Bologna Process) and is active in establishing agreements and memorandum of understanding with other universities around the world, currently, TIU is offering its student's exchange opportunities in countries such as Germany, Poland, Italy, and the USA and it is also included in the ERASMUS and Fulbright programs (Home-TIU, n.d.).

\subsection{The problem statement:}

The problem of the research can be highlighted by the following statement, "despite the facilities that TIU provides to their students, few numbers of students are applying for the exchange programs".

Many studies have been conducted to identify the reasons behind such shortage in participation such as (Curaj, 2015) which identified 6 factors which impact student participation in the European Union, these factors were Recognition, Tuition Fees and Restrictions, Financial Support, Social Support, Public and Media Perception, Brain Gain and Brain Drain. The studies are mostly conducted in countries in which getting a visa to study abroad is not an issue, but for Iraq being the $2^{\text {nd }}$ worst passport (Passport Index, 2020) in the world getting a visa might be one of the major issues.

\subsection{Purpose:}

- $\quad$ The study aims to investigate the factors limiting student participation in the exchange programs offered by TIU. 


\subsection{Research Question:}

1. Is the Visa limiting the students from participating in the exchange program?

2. What are the factors limiting student participation in Student Exchange Programs?

\section{Literature review:}

One of the important goals of both nations and universities is the Improvement of the international competencies of the students at the university level (Li, Olson, \& Frieze, 2013). Students are no longer living in an isolated environment; internet and the globalization have created a need from the student's side for ways to increase their knowledge and being exposed to different educational systems and cultures. thus, higher education institutions are collaborating and started to encourage students to study abroad by joining Students Exchange Programs and become an international student (Soejatminah, 2018). In his book, Harari defined the student's Exchange Program as "the international movement of scholars and students" (Harari, 1992, p. 69) while Murphy-Lejeune defined the student mobility as "a short-term stay abroad, usually one academic year of nine to twelve months duration" (Murphy-Lejeune, 2002, p. 21).

Exchange programs give a change for students from different universities to study for a semester or two. The name of the sending university is "home university" and the name of the receiving university is "host university, commonly home university will set a minimum GPA for students to be eligible to participate in such a program and the student should also meet the requirement of the host university as well, such as a certain level of language and GPA. Both universities should agree on the number of exchange students and if one part is not satisfied with the agreement it may come to an end (Atalar, 2020).

\subsection{The aim, benefits, and limitations of the student's exchange program:}

Students exchange programs have various goals and benefits, Patience A Sowa (2002) identified student exchange program as a chance for the student to roam around the world and find more about him/her self and to improve and increase the relationship between countries and share the culture, furthermore, improving the language skills and make contact with new students in the host university. (Sowa, 2002)The experience of Student Exchange Program that the higher education provides for the students has many features but in contrast, it has many limitations that the students should aware of, for example in the USA large number of students are not able to participate in Exchange program due to factors such as credit transferring and they feel that studying abroad is extending their study duration. Moreover, high tuition fees can also be a factor of which discourage students from participating in the exchange program (Nyaupane, 2011). For instance, Fulbright which is an International Institute in the USA offers different types of scholarships for USA students and international students. This Institute aims to make society educated by teaching people and help them to get experience abroad, this program helps the students to continue their life and find new work opportunities in other countries such as New Zealand, Australia, the USA, and UK (Akli, 2013).

Another opportunity and experience that the students can take during their study is joining the ERASMUS program. ERASMUS program which stands for (European Region Action Scheme for the Mobility of University Students) is a program funded by the European Commission, this program is intended to help students getting scholarships to study in one of the European countries, this could be valid in the universities where the education system is based on the bologna process, the merits of the bologna process are Credit Transfer System and transparency in qualifications (Juvan, 2011). The benefit of the bologna process is to provide facilities to the students to engage with exchange programs that universities offer to their students without facing a problem, the universities in Australia work on applying the bologna system in their universities to match with European universities. U.K, New Zealand, and Canada universities have a noticeable glitch in the outgoing and incoming students despite they are an English speaker and they are following the bologna system (Zahavi, 2019). Stephanie Doyle (2011) finds the reasons in his research and he mentions the elements that affect the student exchange program are:

3. Misunderstanding of the benefit of the exchange program.

4. Limited ongoing support to the students.

5. Problems with integration between the study program of the home university and host university (Stephanie Doyle, 2011). 
Many researchers conducted studies about the factors that affect the students from participating in the exchange programs in different universities and different countries. In Singapore (Mazzarol, 2002) argue that the decision to study abroad requires three distinctly different stages: (1) the student intends to study internationally; (2) the selection of the country; and (3) the institution. Mazzarol also identified six factors that influence a host country's selection: (1) host country knowledge and awareness; (2) personal suggestions; (3) financial issues(4) atmosphere; (5) based on geographic proximity; and the Behavioral factors affected the educational choices. In 2007, Manrginson mentioned the factors such as peers and family and the global educational establishment showed the impact on these decisions (Marginson, 2007). As for the universities in the united states of America (Naffziger, 2008) conducted a survey to investigate the factors that affect the students participating in studying abroad programs. Their data were based on a web-based survey distributed to the students and various types of questions the students were asked including (age, gender and other questions related factors that affect the studying abroad such as personal travel, level of parents' education and the money, curriculum, family, and safety and cultural concerns). The findings were a list of factors affecting the students' such as factors that related to the student's personality and the teaching style also the fear and expanses. The authors suggested that the administrative staff of American universities should encourage the students and explain the benefit of studying abroad and conduct some initiatives to increase the awareness of students about the benefit of studying abroad.

Moving to New Zealand (Doyle S. G., 2010) made an interview with the undergraduate students and secondary students, to investigate why the students are not participating in an exchange program, they found that the main problem is that the cost of studying abroad was one of the problems, then the identified that the second obstacle is leaving friends and family and the last on that they faced during doing interview and survey with students is the lack of knowledge about studying abroad and the found that the students are afraid to not get accepted in the foreign universities because of their grades. (Li Phang, 2013), determined Three types of factors influence the decision of international students as their destination for the study, which includes connectivity, place, and social factors. In the UK the Sussex Centre for Migration Research, University of Sussex, and the Centre for Applied Population Research, University of Dundee, did a report about the student's motility, by distributing a survey among 1200 students and the study identified four factors deterring the students from studying abroad:

- $\quad$ Financial issues

- institutional limitations

- language problem

- $\quad$ attitudes of the students (Migration Resarch \& Dandee, 2014).

In their report about the opportunities for international experience in the UK, CFE mentioned that the lack of information can make it hard for students to differentiate between good and bad exchange opportunities, such a factor can cause a negative experience for students which might make them unwilling to pursued another international experience in the future or for a negative image about the host country. On the other hand, even if the experience was well organized, factors such as homesickness and the shock of culture and feel like an outsider can also lead to a negative experience (CFE research, 2014).

Bandyopadhyay in 2015, conducted a conceptual framework to study the factors that limit university students from participating in studying abroad programs. Their framework explained the interrelationships between the factors that affect the decision of the students to participate in study abroad programs. The findings were factors that affect the students from participating in programs such as duration and cost plus the demographic factors, such as race and gender. the author suggested that to increase the current participant level the university needs to make a good advertisement for this program and attract the students (Bandyopadhyay, 2015).

In 2015, Barchet used personal interviews to collect his data. Their results showed that the characteristics of the course are significant when deciding to study abroad while the features of the country are less significant. Administrative processes were of minor importance, while cost problems were less important too (Aguilera-Barchet, 2015). Another interesting study conducted by MARCINIAK and WINNICKI in 2019 on a sample of Polish students to determine the benefits and risks related to the exchange programs identified that for women, the main motivation to study abroad was the desire to travel and to learn or develop language skills, whereas for men it is mostly about having good times and fun. On the other hand, the risks were Commercial income, academic colonization, and challenges in delivering high-quality education (Dominika \& Michał, 2019). 


\section{Methodology}

\subsection{Participants:}

The study targeted the students of business at Tishk International University and out of 260 students 100 students filled the survey and only 94 valid surveys are used to reach the results.

\subsection{Data collection instrument:}

After checking the literature for the factors influencing the student's attitude towards studying abroad a focus for the challenges was made and the result was a survey questionnaire which was derivative from (Doyle, Gendall, \& Meyer, 2010) and (Sussex Centre for Migration Research, 2004) and (Stroud, 2015). the survey questionnaire consisted of three-part, the first part collected general information about the sample, and it consisted of 9 questions that covered information related to the demographics, education, languages, and travel aspects of the sample. The second part focused on the awareness of the student exchange opportunities offered by the university and was consisted of five questions. The last part was consisted of 15 questions and checked the sample attitude toward the factors deterring the participation in such programs, in this part the study add a question about the visa as it was not mentioned in most of the studies and it is essential to answer the research question.

\section{Results}

\subsection{General information}

The survey reported that (55\%) of the sample were males and (45\%) were females, and the majority were in their $2^{\text {nd }}$ and $3^{\text {rd }}$ year of study. When asked about their residency, (83\%) reported that they are living with their families, and concerning how they are financing their study, $(71 \%)$ said that family is taking this responsibility while (28\%) are selffinancing. The sample was asked about the languages they know and Kurdish (being the official language of Erbil city) came first with (90\%) followed by English (88\%) then Arabic (59\%) and finally Turkish (38\%) and Turkish was the language that most students are learning in the university. Since the visa is related directly to the study, students were asked about their passport origin and whether they have faced any issue in applying for a visa and the results showed that (94\%) own an Iraqi passport and (56\%) did not face any issue while (27\%) did, and when it comes to their travel tendency (55\%) reported that they have been abroad more than 3 times which indicate a high mobility level.

\subsection{Study Abroad}

This section started by checking the student's awareness, interest, and consideration of studying abroad in the university, and the results showed that (65\%) are aware, $(60 \%)$ are interested but only (23\%) have seriously considered participating, and (37\%) have thought about it but did not take any action which can be considered as good results when it comes to their interest but awareness and turning this interest into action needs more effort. To direct such effort the next question asked the students about their source of information about exchange programs and the results showed that word of mouth represented by friends (30\%) is the top medium followed by lecturers and employees (23\%), the international relations office of the university represented only $(11 \%)$ of the sample and the events conducted by the office represented (6\%) only. The lowest medium was brochures which represented (4\%) only.

Many studies have identified finance as a major obstacle which limits students from participating, thus the next question and since Iraq is not having many options in terms of scholarships and funds especially for studying abroad asked the students whether their family will support their decision if they have decided to study abroad and the results showed that (50\%) will get their family support including financial support and $17 \%$ will get their support but not financially while $9 \%$ stated that they will not get any support and $24 \%$ did not know. 


\section{EJMSS Eurasian Journal of Management \& Social Sciences}

4.3 Attitudes to Obstacles to Student Exchange Programs

Table (1) Attitudes to Obstacles to Student Exchange Programs

\begin{tabular}{|c|c|c|c|}
\hline Statement & $\begin{array}{c}\% \\
\text { Disagree }\end{array}$ & $\%$ Neutral & \% Agree \\
\hline $\begin{array}{l}\text { I would find it too difficult to study in a country } \\
\text { where the teaching was not in English. }\end{array}$ & 20 & 22 & 57 \\
\hline $\begin{array}{l}\text { I would much rather go overseas after finishing } \\
\text { my degree than study abroad while I am still } \\
\text { doing my degree }\end{array}$ & 19 & 33 & 48 \\
\hline I would find it difficult to leave my family. & 31 & 31 & 38 \\
\hline $\begin{array}{l}\text { Study overseas could interrupt my degree study } \\
\text { and might affect my academic performance } \\
\text { here. }\end{array}$ & 28 & 34 & 38 \\
\hline $\begin{array}{l}\text { It would be too expensive for me, so I could not } \\
\text { afford to study overseas. }\end{array}$ & 36 & 28 & 36 \\
\hline $\begin{array}{l}\text { The offers that provided by the university are } \\
\text { not suitable for me }\end{array}$ & 33 & 32 & 35 \\
\hline $\begin{array}{l}\text { I do not feel confident I could do well at an } \\
\text { overseas university. }\end{array}$ & 43 & 29 & 29 \\
\hline $\begin{array}{l}\text { My grades are not good enough to be accepted } \\
\text { to study abroad. }\end{array}$ & 54 & 15 & 31 \\
\hline I would find it difficult to leave my friends. & 51 & 29 & 20 \\
\hline $\begin{array}{l}\text { I would find it difficult to leave my work and } \\
\text { find another when I got back. }\end{array}$ & 46 & 29 & 26 \\
\hline $\begin{array}{l}\text { My department does not offer any opportunity } \\
\text { to study abroad. }\end{array}$ & 45 & 30 & 26 \\
\hline I am afraid that I will not get a visa. & 44 & 25 & 32 \\
\hline I worry about living in another country/culture. & 61 & 22 & 17 \\
\hline I do not know enough about study overseas & 29 & 39 & 32 \\
\hline I do not feel comfortable living in a dorm. & 47 & 20 & 33 \\
\hline $\begin{array}{l}\text { I am not sure if I would be eligible for a student } \\
\text { loan or allowances or be funded while I was } \\
\text { overseas. }\end{array}$ & 31 & 46 & 23 \\
\hline $\begin{array}{l}\text { Insufficient information about the available } \\
\text { opportunities for student exchange programs. }\end{array}$ & 13 & 55 & 32 \\
\hline
\end{tabular}

As seen in table (1) above the results of the sample attitudes towards the obstacles that are deterring them from participating in student exchange programs the language, finishing the degree first, longer study and academic performance, leaving family and finance were the top obstacles. Most respondents (57\%) agreed that it would be too difficult to study in a country where the teaching was not in English which is fair since the study in TIU is in English. Similarly, they have agreed $(48 \%)$ that they would rather go overseas after finishing their study, this answer correlates positively with the fear of making their study longer or affecting their academic performance which they agreed with (38\%). Leaving the family was also a challenge (38\%) since most of the students (83\%) are living with their families. Finance divided the sample between agreeing (36\%) and disagreeing (36\%) in terms of the study being too expensive and they cannot afford it. Finally, (35\%) reported that the offers provided by the university are not suitable for them. 


\section{EJMSS Eurasian Journal of Management \& Social Sciences}

On the other hand, other obstacles such as low grades, confidence, leaving friends, leaving work, no offers from the department, worry about living in another country/culture, lack of information about exchange programs, living in a dorm, and getting a visa were denied by the sample and the results showed that the students do not see them as an obstacle especially living in another country/culture $(61 \%)$ and grades (54\%). As for the visa, surprisingly, the students did not see it as a major issue, and only (32\%) stated that they consider it as a challenge since (56\%) of the sample reported that they did not face any issue with getting a visa before even though (94\%) are holding the Iraqi passport. Finally, the sample was neutral when it comes to being not sure of getting a fund or a loan while studying abroad and that the information is insufficient when it comes to the available opportunities.

\subsection{Findings:}

The study aims to study the factors related to student participation in student exchange programs. The key findings reported that the students are mostly having an Iraqi passport, but this did not limit their mobility that 55\% have traveled more than three times and 56\% did not face any issue in getting a visa. 44 the study assumed that the visa is an important factor limiting the students but $44 \%$ disagreed with such a claim. The language was reported as a factor limiting the student participation in term of studying in a university which does not teach in English. Kurdish is the main language in KRG and 90\% reported that they speak Kurdish followed by English. Kurdish courses are not available in other countries thus students need at least English to be eligible to study abroad. The study also showed that students are aware and interested in the exchange programs but they are not seriously considering the participation, this is related to the fact that word of mouth is the main way for students to get information about the exchange programs, represented by friends $30 \%$ and $23 \%$ lectures and employees. The IRO office and the events conducted by it are not that of importance to students $11 \%, 6 \%$ respectively. Finally, the study identified a list of factors that affect the students which included, the above-mentioned language issue, looking for a full degree study and not a onesemester which the university is offering this limitation is leading to the fear of interrupting the study or getting the academic performance affected limitation, moreover, the offers of the university are not enough and attachment to family was also reported as a barrier since $83 \%$ of students are livening with their families. Finance was reported by the sample as equally as a limitation and not.

\section{Conclusion:}

This paper is designed to analyze which factors are affecting student participation in student exchange programs at Tishk International University. TIU is offering all the programs in English (except for Law faculty which is in Arabic) and follows the bologna process, furthermore, it is a member of the ERASMUS program and has more than 70 memorandums of understanding with different universities and institutions around the world. This effort aims to support student's mobility yet, only a few numbers are applying for the exchange programs. The study posited that visa, language, and fees are the main factors limiting the student. The study concluded that based on the students answers to the survey, the visa is not an issue despite having an Iraqi passport, but language, timing, attachment to family, study duration, academic performance, finance, and limited options are the main factors limiting student participation in the exchange programs.

The study recommends that policymakers should increase the exchange opportunities and look for methods to fund the exchange programs, furthermore, more awareness campaigns can be conducted to share the importance of the exchange programs and to target families, as they play a role in limiting the capture of this opportunity from the student's side. It is also recommended for researchers to conduct a study that interviews the students who participated in the exchange program to measure the effectiveness of the program and to investigate the benefits and challenges related to it. Lastly, the universities can get benefits from the students who participated in exchange programs by employing them as ambassadors who share awareness and encourage students to participate and provide feedback as well. 


\section{EJMSS Eurasian Journal of Management \& Social Sciences}

\section{References}

Aguilera-Barchet, B. (2015). higher education for the twenty-first century. Wilfried Martens Centre for European Studies.

Akli, M. (2013). Study abroad and cultural learning through Fulbright and other international scholarships: A holistic student development. Journal of International Students, 2(1), 1-9.

Atalar, A. (2020). Student Exchange: The First Step Toward International Collaboration. In In Successful Global Collaborations in Higher Education Institutions (pp. 63-71). Cham: Springer.

Bandyopadhyay, S. \&. (2015). Factors influencing student participation in college study abroad programs. Journal of International Education Research (JIER), 11(2), 87-94.

CFE research. (2014). Research and Analysis of the Benefits of International Education Opportunities. Leicester: British Council.

Curaj, A. M. (2015). The European higher education area: Between critical reflections and future policies. Springer.

Dominika, M., \& Michał, W. (2019). international student exchange-motives, benefits. s i l e s i a n u n i v e r s i t yof te chnolog y publishinghous e.

Doyle, S. G. (2010). An investigation of factors associated with student participation in study abroad. Journal of Studies in International Education, 14(5), 471-490.

Doyle, S., Gendall, P., \& Meyer, L. (2010). An Investigation of Factors Associated With Student Participation in Study Abroad. An Investigation of Factors Associated With Student Participation in Study Abroad, 14, 471 490.

Harari, M. (1992). The Internationalization of the Curriculum. In Bridges to the future: Strategies for internationalizing higher education (pp. 52-79).

Home-TIU. (n.d.). Retrieved from Tishk International University: https://tiu.edu.iq/iro/

Juvan, E. \&. (2011). Erasmus Exchange Program: Opportunity for professional growth or sponsored vacations? Journal of Hospitality \& Tourism Education, 23(2), 23-29.

Li Phang, S. (2013). Factors influencing international students' study destination decision abroad. Gothenburg, Sweden: Master Thesis.

Li, M., Olson, J., \& Frieze, I. (2013). Students' Study Abroad Plans: The Influence of Motivational and Personality Factors. Frontiers: The Interdisciplinary Journal of Study Abroad, 23, 73-89.

Marginson, S. \&. (2007). To rank or to be ranked: The impact of global rankings in higher education. Journal of studies in international education, 11(3-4), 306-329.

Mazzarol, T. a. (2002). "'Push-pull" factors influencing international student destination choice". International Journal of Educational Management, 16(2), 82-90. doi:https://doi.org/10.1108/09513540210418403

Migration Resarch, S. C., \& Dandee, U. (2014). International Studnets Mobility. UK.

Murphy-Lejeune, E. (2002). Student mobility and narrative in Europe: The new strangers. London: Routledge.

Naffziger, D. W. (2008). Factors influencing study abroad decisions among college of business students. International Business: Research, Teaching and Practice, 2(1), 39-52.

Nyaupane, G. P. (2011). Study abroad motivations, destination selection and pre-trip attitude formation. International Journal of Tourism Research, 13(3), 205-217.

Passport Index. (2020). Global Passport Power Rank 2020. Retrieved 24 1, 20, from Passport Index: https://www.passportindex.org/byRank.php

Soejatminah, S. (2018). ASEAN University Network in Enhancing Student Mobility. Journal of Interdisciplinary Studies in Education, 7(1), 19-33.

Sowa, P. A. (2002). How valuable are student exchange programs? New directions for higher education, 2002(117), 63-70.

Stephanie Doyle, P. G. (2011). An investigation of factors associated with student participation in study abroad. Journal of Studies in International Education, 14(5), 471-490. 


\section{EJMSS Eurasian Journal of Management \& Social Sciences}

Stroud, A. H. (2015). Should I Stay or Should I Go?: Factors Impacting the Decision to Study Abroad Among Students Who Have Expressed Intent. Doctoral Dissertations.

Sussex Centre for Migration Research, U. o. (2004). International student mobility. UK: Issues Paper commissioned by HEFCE, SHEFC, HEFCW, DEL, DfES, UK Socrates Erasmus Council, HEURO BUTEX, and the British Council. .

Zahavi, H. \&. (2019). The Bologna Process: an international higher education regime. European Journal of Higher Education, 9(1), 23-39. 